\title{
The effect of dehydroemetine on isolated
}

\section{guinea-pig atria}

\author{
A. O. DUROTOYE* AND L. A. SALAKO
}

Department of Pharmacology, University of Ibadan, Ibadan, Nigeria

\section{Summary}

1. The mechanism of the inhibitory effect of dehydroemetine on the heart was investigated using spontaneously contracting isolated guinea-pig atria.

2. In normal Locke solution, dehydroemetine caused a reduction in the rate and amplitude of contraction of the atria. The effect was antagonized by adrenaline and augmented by acetylcholine.

3. Increasing the potassium concentration of the bathing medium increased the inhibitory effect of dehydroemetine on the atria, while decreasing the potassium concentration antagonized the effect of dehydroemetine.

4. The character of the inhibitory effect of dehydroemetine on the atria altered when the sodium concentration of the bathing solution was lowered to $75.6 \mathrm{mmol}$. In the normal sodium medium arrest of beat by dehydroemetine was gradual ; in the low sodium medium, it was abrupt.

5. In the low, as in the normal sodium medium, the inhibitory effect of dehydroemetine was more marked the higher the potassium concentration of the bathing medium.

6. In both standard Locke solution and Locke solution containing $75.6 \mathrm{mmol}$ sodium, the effect of dehydroemetine closely mimicked that obtained by adding excess potassium to the solution.

7. On the basis of the foregoing it was suggested that dehydroemetine acts by increasing the permeability of the myocardial cell membrane to potassium thereby leading to the accumulation of potassium in the extracellular space.

\section{Introduction}

Recent studies have shown that the relatively new antiamoebic drug, dehydroemetine, exerts important effects on myocardial action in vivo and in vitro. Thus in man, in therapeutic doses (1-2 mg/ $\mathrm{kg}$ i.m. daily for 1-2 weeks), it causes hypotension, tachycardia, and electrocardiographic changes characterized by $T$ wave flattening or inversion, prolongation of QTc interval, and QRS voltage drop (Gonzalez de Cossio, 1960 ; Powell, Wilmot, MacLeod \& Elsdon-Dew, 1965; Lister, 1968). In anaesthetized cats and rats it produces hypotension with or without bradycardia, and changes in the electrocardiogram consisting of abnormal QRS complexes, bradycardia, and impaired intraventricular and atrio-ventricular con- 
duction (Herrero, Brossi, Faust \& Frey, 1960 ; Salako \& Durotoye, 1971). In the isolated perfused rabbit and guinea-pig heart it causes a reduction in both the rate and amplitude of contraction and reduces the maximum rate at which the isolated guinea-pig atria could be electrically driven without missing beats (Durotoye \& Salako, 1971). On the strength of its prolongation of the 'effective' refractory period of the isolated guinea-pig atria, Durotoye \& Salako (1971) suggested that the cardiovascular effects of dehydroemetine might be due to a quinidine-like action on the heart. In this study, the effect of dehydroemetine on the isolated guinea-pig atria has been investigated in greater detail with a view to further elucidating the mechanism of the drug's action on the heart.

\section{Methods}

Eighty guinea-pigs of either sex weighing between 400 and $600 \mathrm{~g}$ were used. The animals were stunned by a blow on the head and killed by exanguination from the common carotid arteries. Both atria were carefully dissected out in one piece avoiding, in particular, damage to the tissue in the pacemaker region. They were suspended in an organ bath containing $70 \mathrm{ml}$ bathing solution at $30^{\circ} \mathrm{C}\left( \pm 0.5^{\circ} \mathrm{C}\right)$. The solution was continuously bubbled with $100 \%$ oxygen. The lower end of the atria was tied to a pair of platinum electrodes which were connected to a Grass Model S8 Square Wave Stimulator (Grass Instruments, Mass, U.S.A.). This enabled the tissue to be electrically stimulated whenever it was desired. The upper end was attached via a fine silk thread to a light Starling's heart lever exerting approximately $1.0 \mathrm{~g}$ tension on the tissue, and writing on smoked paper with 7-fold magnification. Each preparation was allowed to equilibrate for $90 \mathrm{~min}$ at the end of which the spontaneous isotonic contractions had become steady in amplitude and rate. Experimental observations were made either in the presence of steady-state function or during the response to experimental procedure. Steady state was presumed to exist when the rate and amplitude of contraction did not change in the course of a minimum of $10 \mathrm{~min}$ observation.

The standard medium in which the tissue was suspended was Locke solution containing double the normal amount of glucose and having the following composition (mmol): sodium chloride $153 \cdot 8$, potassium chloride $5 \cdot 6$, calcium chloride $2 \cdot 1$, sodium bicarbonate 5.95 , glucose $11 \cdot 1$. It had a $\mathrm{pH}$ of 8.0 and an osmolality of 350 milliosmoles per $\mathrm{kg}$ of water. Concentrations of potassium and sodium in the bathing medium were varied by changing the concentrations of potassium chloride and sodium chloride respectively. Increases in the concentration of potassium were produced by adding appropriate volumes of a $1.4 \mathrm{M}$ potassium chloride solution to $70 \mathrm{ml}$ of the standard medium. Osmotic balance was not attempted when only the potassium chloride concentration was changed, but reduction in sodium chloride concentration was balanced osmotically by the addition of $11.9 \mathrm{~g}$ sucrose for each gramme of sodium chloride removed from the standard Locke solution.

The drugs used were dehydroemetine dihydrochloride (Roche), adrenaline injection B.P. (Antigen) and acetylcholine chloride (Roche). The concentrations were expressed in $\mathrm{g} / \mathrm{ml}$ calculated as the salt.

Results presented in Figures and the Table are mean values \pm standard errors of the means. Comparisons of the results were made using Student's $t$ test. 


\section{Results}

\section{Atria in Locke solution}

Dehydroemetine $0.15,0.45$ and $1.5 \times 10^{-6} \mathrm{~g} / \mathrm{ml}$ reduced both the spontaneous frequency and amplitude of contraction of isolated guinea-pig atria. The effect developed gradually until a new steady level was reached 5-20 min after adding the drug. The minimum effective concentration was $0.15 \times 10^{-6} \mathrm{~g} / \mathrm{ml}$. The addition of $1.5 \times 10^{-5} \mathrm{~g} / \mathrm{ml}$ caused complete cessation of spontaneous activity in 11 out of 24 atria, and higher concentrations regularly produced atrial arrest. Arrest of beat was always preceded by irregularities of rate and rhythm. The effect was reversible even after spontaneous activity had been completely abolished by dehydroemetine (Fig. 1). In the latter case, however, the readiness with which the effect could be reversed diminished with the length of time between cessation of activity and the washing out of the drug. When the drug was washed out within one minute of the arrest of beat, recovery was immediate; after $10 \mathrm{~min}$, several washings were needed and there was a variable period of 5-10 min between the removal of the drug and the return of activity; after $30 \mathrm{~min}$ the effect was not reversible by repeated washing over a period of up to 1 hour. Concentrations of $1.5 \times 10^{-5} \mathrm{~g} / \mathrm{ml}$ and above which were capable of producing the irreversible change were therefore regarded as toxic concentrations under the experimental conditions.

Effect of adrenaline, acetylcholine and electrical stimulation. When added to the bathing solution within $30 \mathrm{~min}$ of the arrest of beat by dehydroemetine, adrenaline $\left(1.5 \times 10^{-6} \mathrm{~g} / \mathrm{ml}\right)$ restored spontaneous contraction, the rate and force rapidly increasing to become greater than before the initial addition of dehydroemetine (Fig. 1). The longer the dehydroemetine-induced period of arrest was allowed to last before adrenaline was added, the longer the time (0-2 min) before the beat was restored. When spontaneous contraction had ceased for over $30 \mathrm{~min}$, adrenaline usually failed to restore it. The antagonism between adrenaline and dehydroemetine was studied further in 6 atria by investigating the chronotropic effects of 5 concentrations of adrenaline in the presence and absence of 3 concentrations of dehydroemetine. The dose-response for adrenaline was first determined in the absence of dehydroemetine, the adrenaline being applied cumulatively every 2 minutes. The solution was then washed off and the tissue allowed to return to a steady state. The procedure was repeated in the same tissue in the presence of each of three concentrations of dehydroemetine $\left(0.15,0.45\right.$ and $\left.1.5 \times 10^{-6} \mathrm{~g} / \mathrm{ml}\right)$

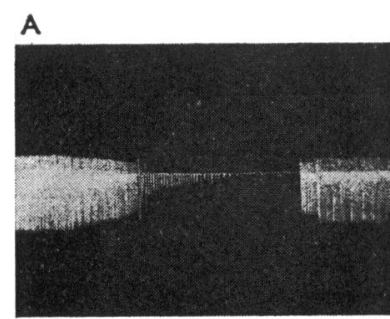

$\Delta$

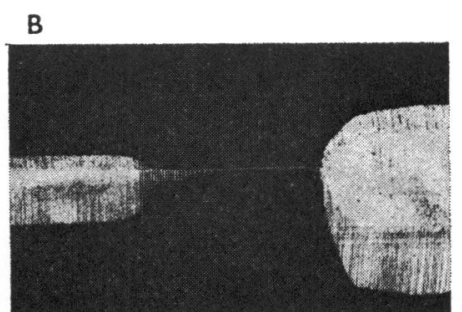

$\triangle$

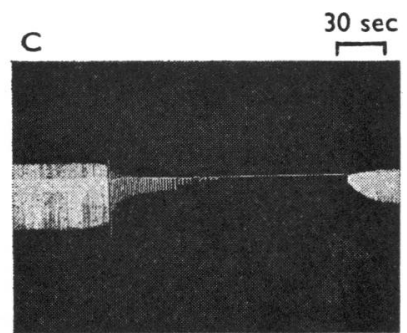

$\Delta$

FIG. 1. Effect of $1.5 \times 10^{-5} \mathrm{~g} / \mathrm{ml}$ dehydroemetine on spontaneous isotonic contractions of the isolated guinea-pig atria suspended in standard Locke solution. At $\triangle$, dehydroemetine $(1 \cdot 5 \times$ $10^{-5} \mathrm{~g} / \mathrm{ml}$ ) was added to the bathing medium. Reversal of dehydroemetine-induced inhibition of atrial contraction occurred on washing $(O$, panel $A)$, on the addition of $1.5 \times 10^{-6} \mathrm{~g} / \mathrm{ml}$ adrenaline (O, panel $B)$ and on direct electrical stimulation of the atria ( + , panel $C)$. 
in turn. The duration of exposure of the tissue to dehydroemetine before determining the dose-response for adrenaline was $20 \mathrm{~min}$ which was sufficient for the effect of dehydroemetine on the atria to become steady. Experiments were discarded if the steady-state rate and amplitude of contraction of the atria at the post-adrenaline washout periods differed from the initial steady-state values by more than 5 per cent. The 3 doses of dehydroemetine caused a reduction in the resting rate of the atria which was completely overcome by adrenaline so that the maximum rate at which the atria could beat under the influence of adrenaline was not altered by the presence of dehydroemetine (Fig. 2). The effect of adrenaline was abolished by previous addition of $10^{-6} \mathrm{~g} / \mathrm{ml}$ propranolol to the solution.

In contrast to adrenaline, acetylcholine $\left(10^{-8}\right.$ and $\left.10^{-7} \mathrm{~g} / \mathrm{ml}\right)$ had no stimulatory effect on atria which had become quiescent under the influence of dehydroemetine. If the rate and amplitude of contraction of the atria had been reduced but not abolished by dehydroemetine, the addition of acetylcholine produced a further decrease which was greater than that which would have been expected in the absence of dehydroemetine.

When spontaneous contraction of the atria was abolished by dehydroemetine, the tissue responded to electrical stimulation $(10 \mathrm{~V}, 1 \mathrm{~ms})$ if this was applied within $30 \mathrm{~min}$ of cessation of activity (Fig. 1). Thereafter the tissue was electrically inexcitable. The effect of electrical stimulation was not prevented by prior addition of propranolol, $10^{-6} \mathrm{~g} / \mathrm{ml}$, to the bathing medium.

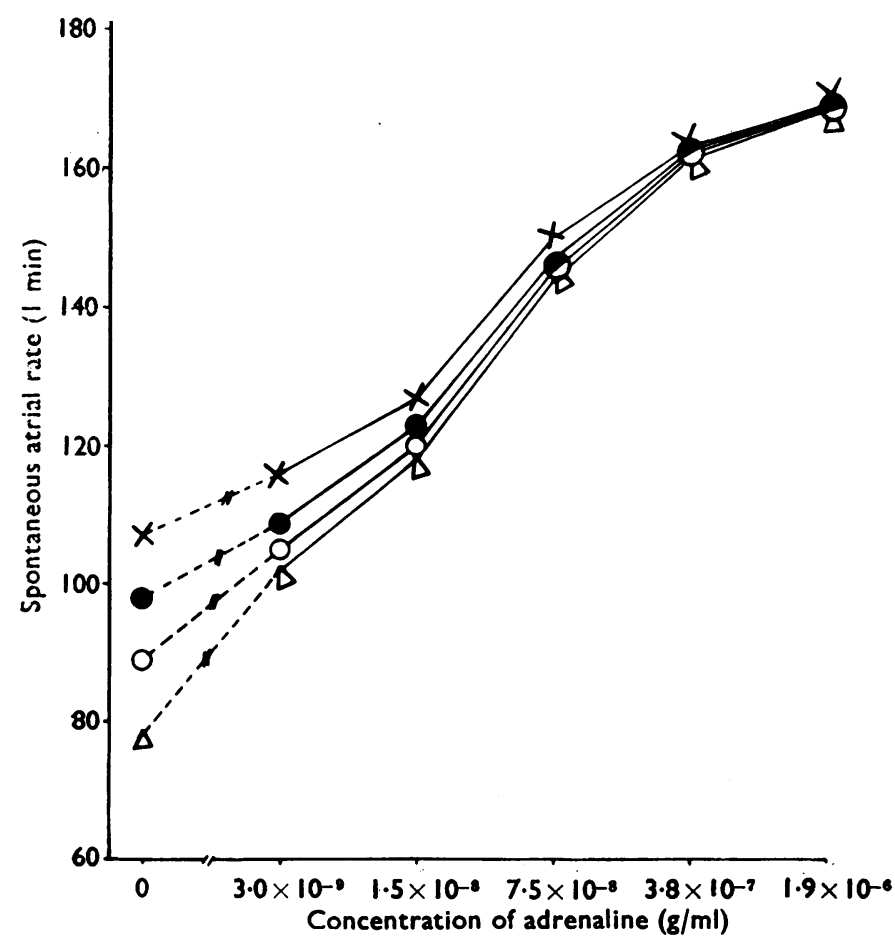

FIG. 2. Atria in normal Locke solution. Graphs showing the antagonism of adrenaline to the negative chronotropic effect of dehydroemetine. $\times$, No dehydroemetine ; $0,0.15 \times 10^{-6}$ $\mathrm{g} / \mathrm{ml}$ dehydroemetine ; $0,0.45 \times 10^{-6} \mathrm{~g} / \mathrm{ml}$ dehydroemetine ; $\triangle, 1.5 \times 10^{-6} \mathrm{~g} / \mathrm{ml}$ dehydroemetine. Each point represents the mean of six experiments. 


\section{Effect of varying the potassium concentration of the bathing fluid}

When potassium chloride was added to Locke solution to achieve a potassium concentration of 13-25 mmol, the spontaneous contraction of atria suspended in the solution progressively diminished in frequency and amplitude and finally stopped. Automaticity could be restored by washing with adrenaline $\left(10^{-6} \mathrm{~g} / \mathrm{ml}\right)$ and by electrical stimulation but not by acetylcholine $\left(10^{-7} \mathrm{~g} / \mathrm{ml}\right)$. The effect of these concentrations of potassium was therefore similar to that of dehydroemetine. If, however, potassium concentration of the bathing solution was raised to $8.4 \mathrm{mmol}$, only a small reduction (5-10\%) in frequency and amplitude of contraction was produced and a new steady state was reached within 5-15 minutes. The influence of increased potassium concentration on the action of dehydroemetine was therefore tested using this concentration of potassium. The results showed that raising the potassium content of the bathing medium to 1.5 times the normal concentration increased the negative chronotropic effect of dehydroemetine (Table 1). In this high potassium medium, $1.5 \times 10^{-5} \mathrm{~g} / \mathrm{ml}$, dehydroemetine always produced cessation of spontaneous contraction of the atria.

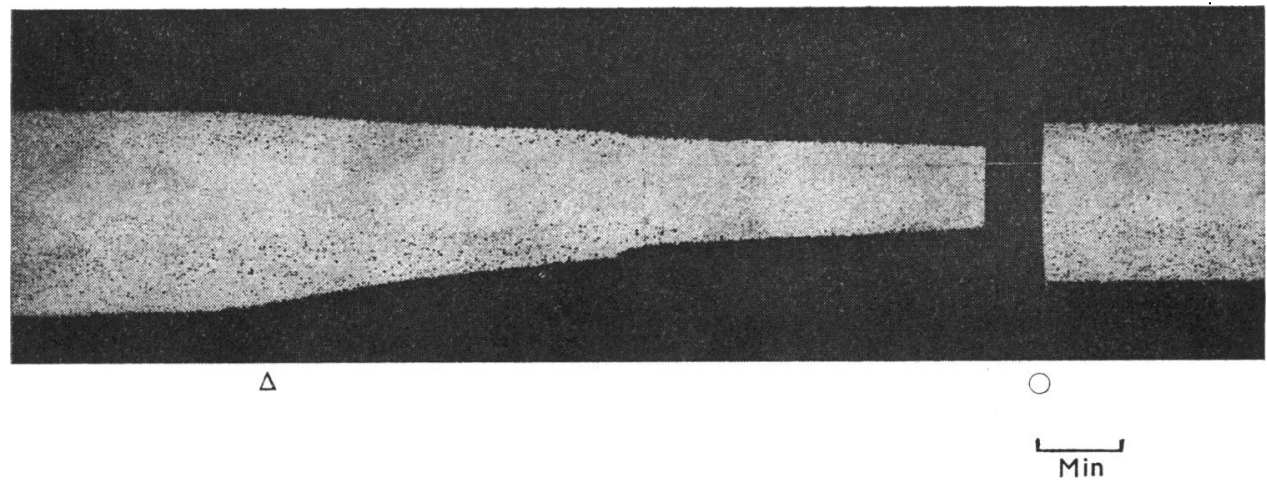

FIG. 3. Atria contracting spontaneously in Locke solution modified to contain $75.6 \mathrm{mmol}$ sodium. Addition of $1.5 \times 10^{-5} \mathrm{~g} / \mathrm{ml}$ dehydroemetine at $\triangle$ caused abrupt atrial arrest after only about $50 \%$ reduction in height and rate of contraction. This effect was reversed by washing, $\bigcirc$.

TABLE 1. Effect of dehydroemetine on rate of contraction of atria suspended in standard and modified Locke solution

Concentration of dehydroemetine $(\mathrm{g} / \mathrm{ml})$

(a) Normal $\mathrm{K}^{+}$; normal $\mathrm{Na}^{+}$solution

(b) $1.4 \mathrm{mmol} \mathrm{K}^{+}$; normal $\mathrm{Na}^{+}$solution Difference between (a) and (b)

(c) $8.4 \mathrm{mmol} \mathrm{K}+$, normal $\mathrm{Na}^{+}$solution Difference between (a) and (c)

(d) Normal K+; $75.6 \mathrm{~mm} \mathrm{Na+}$ solution

(e) $1.4 \mathrm{mmol} \mathrm{K}+; 75.6 \mathrm{mmol} \mathrm{Na}{ }^{+}$solution Difference between (d) and (e)

Number of experiments is given in parentheses.

\begin{tabular}{|c|c|c|}
\hline \multicolumn{3}{|c|}{$\begin{array}{c}\text { Reduction in rate as } \% \text { of control steady-state } \\
\text { value }+ \text { S.E. }\end{array}$} \\
\hline $0.15 \times 10^{-6}$ & $\begin{array}{l}\text { value } \pm \text { S.E. } \\
0.45 \times 10^{-6}\end{array}$ & $1.5 \times 10^{-6}$ \\
\hline $\begin{array}{l}1.6 \pm 0.3 \\
0.9 \pm 0.3 \\
0.7 \pm 0.4 \\
P<0.2 \\
6.9 \pm 0.9 \\
5 \cdot 3 \pm 0.9 \\
P<0.001 \\
0.3 \pm 0.3 \\
0.0 \pm 0 \\
0.3 \pm 0.3 \\
P<0.4\end{array}$ & $\begin{array}{c}4.9 \pm 0.7 \\
3.3 \pm 0.5 \quad(7) \\
1.6 \pm 0.8 \\
P<0.1 \\
26.7 \pm 3.6 \\
21.8 \pm 3.4 \\
P<0.001 \\
1.2 \pm 0.6 \\
0.8 \pm 0.8 \\
0.4 \pm 1.0 \\
P<0.7\end{array}$ & $\begin{array}{c}22.2 \pm 3 \cdot 3 \text { (7) } \\
7 \cdot 5 \pm 0.7 \\
14.7 \pm 3.4 \\
P<0.005 \\
41.8 \pm 2.9 \\
19.6 \pm 4.0 \\
P<0.001 \\
11.0 \pm 1.6 \\
4.0 \pm 1.2 \\
7.0 \pm 2.0 \\
P<0.01\end{array}$ \\
\hline
\end{tabular}


The influence of reduced potassium concentration on the action of dehydroemetine was studied using Locke solution which differed from the standard only in containing one-quarter the normal concentration of potassium. In one series of 6 experiments, atria suspended in standard Locke solution were treated with $1.5 \times$ $10^{-5} \mathrm{~g} / \mathrm{ml}$ dehydroemetine. As soon as the beat was arrested, the bath fluid was changed to dehydroemetine in Locke solution containing $1.4 \mathrm{mmol}$ potassium. The beat returned, increased in rate and amplitude, but never reached the initial resting level. When conditions again became steady, the bath fluid was changed back to dehydroemetine in Locke solution containing normal potassium and the beat was immediately arrested. A study of the effect of 3 concentrations of dehydroemetine $\left(0 \cdot 15,0.45\right.$ and $\left.1.5 \times 10^{-6} \mathrm{~g} / \mathrm{ml}\right)$ on atria suspended in Locke solution containing $1.4 \mathrm{mmol}$ potassium showed that at all these concentrations, the negative chronotropic effect of dehydroemetine was partially antagonized by the reduced external potassium concentration (Table 1).

In the low and high potassium media the characteristics of the inhibitory effect of dehydroemetine were the same as in the normal potassium medium-progressive diminution in rate and amplitude leading either to a new steady state or to a gradual cessation of beat.

\section{Effect of varying the sodium concentration in the bathing fluid}

When atria contracting in standard Locke solution were tranferred to Locke solution containing $75.6 \mathrm{mmol}$ sodium, an immediate increase in amplitude of contraction was observed. A new steady state was attained within 10-15 min of transferring to the low sodium solution and the steady state persisted unchanged during observation periods lasting 90-120 minutes. Locke solution containing $51.7 \mathrm{mmol}$ sodium failed to maintain automaticity in 4 out of 8 atria tested. Cessation of contraction occurred abruptly within $30 \mathrm{~min}$ of changing to the $51 \cdot 7$ mmol sodium medium and was preceded by $25-50 \%$ reduction in amplitude and rate. The influence of reduced external sodium concentration on the action of dehydroemetine was therefore studied using Locke solution containing $75.6 \mathrm{mmol}$ sodium. In this medium $1.5 \times 10^{-5} \mathrm{~g} / \mathrm{ml}$ dehydroemetine caused arrest of atrial contraction within 5-10 min (6 atria). The effect was similar to that of reducing the external sodium concentration to $51.7 \mathrm{mmol}$-an initial decrease in amplitude and rate of between 50 and $75 \%$ of control level followed by abrupt cessation of contraction (Figure 3). Addition of $0.15,0.45$ and $1.5 \times 10^{-6} \mathrm{~g} / \mathrm{ml}$ dehydroemetine caused a small reduction in the rate (Table 1) and amplitude of contraction but did not cause atrial arrest during an observation period of 30 minutes.

\section{Effect of varying the concentrations of both potassium and sodium in the bathing fluid}

The effect of dehydroemetine on atrial contraction was tested using solutions containing: (a) $75.6 \mathrm{mmol}$ sodium chloride and $8.4 \mathrm{mmol}$ potassium chloride, and (b) $75.6 \mathrm{mmol}$ sodium chloride and $1.4 \mathrm{mmol}$ potassium chloride, after preliminary experiments had shown that regular spontaneous contractions of the atria were maintained in these solutions for at least 2 hours.

In solution (a) dehydroemetine $\left(0.15,0.45,1.5 \times 10^{-6}\right.$ and $\left.1.5 \times 10^{-5} \mathrm{~g} / \mathrm{ml}\right)$ produced cessation of spontaneous contraction in all six atria tested after intervals 
varying from $10 \mathrm{~s}$ with the highest to $30 \mathrm{~min}$ with the lowest concentration. The cessation of beat was abrupt with only a small reduction in frequency and amplitude preceding it. In solution (b) $1.5 \times 10^{-5} \mathrm{~g} / \mathrm{ml}$ dehydroemetine caused an abrupt arrest of atrial contraction after a small reduction in rate and amplitude. Dehydroemetine, $0.15,0.45$ and $1.5 \times 10^{-6} \mathrm{~g} / \mathrm{ml}$, did not produce atrial arrest during 30 min observation but caused a reduction in the rate of spontaneous contraction of the atria, the reduction being of smaller magnitude than that produced in Locke solution containing $75.6 \mathrm{mmol}$ sodium and normal potassium (Table 1).

Abrupt cessation of atrial contraction similar to that observed with dehydroemetine in solutions (a) and (b) was also observed in the absence of dehydroemetine if potassium concentration was increased to $11.2 \mathrm{mmol}$ while keeping the sodium concentration at $\mathbf{7 5 . 6} \mathrm{mmol}$.

\section{Discussion}

The results of this study show that dehydroemetine in low doses produces a reversible negative chronotropic and inotropic effect on isolated spontaneously contracting guinea-pig atria. The effect is reversed by adrenaline but not by acetylcholine. The action of dehydroemetine thus differs from that of quinidine which is reversed by acetylcholine (Armitage, 1957; Vaughan Williams, 1958; Johnson \& Robertson, 1958) but not by adrenaline (Johnson \& Robertson, 1958).

In both the normal sodium and in the low sodium media, the effect of dehydroemetine mimics that of potassium excess. In addition, the effect of dehydroemetine is augmented by raising the potassium concentration of the bathing solution and opposed by lowering potassium concentration. These observations suggest that the action of dehydroemetine involves a change in the distribution of potassium between the intracellular and extracellular spaces.

It has been shown that the potassium permeability of cardiac muscle membrane varies directly with the external concentration of potassium (Carmeliet, 1960), and that raising the external potassium concentration reduces the rate of spontaneous contraction of the atria (Toda \& West, 1967). If dehydroemetine acts by increasing the permeability of the cardiac muscle membrane to potassium thereby allowing potassium to accumulate in the extracellular space, then augmentation of its negative chronotropic effect by raised potassium concentration of the bathing medium would be expected. Acetylcholine increases potassium permeability of the myocardial cell membrane (Burgen \& Terroux, 1953) and also, predictably, increases the negative chronotropic effect of raised external potassium concentration (Toda \& West, 1967). The negative chronotropic effect of acetylcholine has been shown in this study to be increased by dehydroemetine which suggests some similarity in the action of the two compounds. Increase in potassium permeability diminishes the rate of diastolic depolarization responsible for rhythmicity and this, in turn, leads to a fall in the rate of spontaneous contraction.

The effect of noradrenaline (and presumably also of adrenaline) on the distribution of ions in cardiac tissue is to produce a net gain of intracellular potassium (Sarnoff, Gilmore \& Wallace, 1965). This effect is the opposite of that suggested for dehydroemetine and would explain the antagonism of the effect of dehydroemetine by adrenaline. 
The failure of a medium containing $51.7 \mathrm{mmol}$ sodium and normal potassium concentrations to sustain automaticity of atria in $50 \%$ of experiments agrees with the findings of Toda \& West (1967). These workers also showed that the external sodium concentration critical for spontaneous activity was directly related to the external concentration of potassium. It follows from their work that at any given level of lowered external sodium concentration, the higher the medium potassium concentration the more readily will automaticity fail with any further drug-induced increase in potassium permeability. Therefore the increasingly inhibitory effect of dehydroemetine to automaticity as the medium potassium was increased from 1.4 through 5.6 to $8.4 \mathrm{mmol}$ in $75.6 \mathrm{mmol}$ sodium solution further suggests that dehydroemetine acts by increasing potassium permeability of the cardiac muscle membrane.

The mechanism suggested for the myocardial action of dehydroemetine on the basis of this study differs from that of quinidine which is thought to act either by reducing the inward sodium current during the phase of rapid systolic depolarization (Vaughan Williams, 1958 ; Johnson \& Robertson, 1958) or by reducing the permeability of the myocardial cell membrane to potassium (Armitage, 1957). The cardiovascular effects of emetine, the natural analogue of dehydroemetine, has also been extensively investigated (see Bianchi, de Marino, de Vleeschhouwer \& Marino, 1965, for references). In isolated rabbit atria this drug has, like dehydroemetine, inhibitory effects on both the spontaneous frequency, and the maximum frequency at which the atria could be electrically driven without losing beats (de Hemptinne, 1965). However, there is no record of any study in which an attempt has been made to explain the mechanism of action of emetine on the myocardium in terms of alterations in electrolyte distribution across the myocardial cell membrane. A comparison between dehydroemetine and emetine in this respect is therefore, at the moment, not possible.

The conclusion from this study that the inhibitory effect of dehydroemetine on spontaneous contraction of the guinea-pig atria might be due to increased potassium permeability of the myocardial cell membrane can at best, only be tentative because of the nature of the study itself. A more definite conclusion must await electrophysiological recording and isotopic measurement of ion fluxes in atria under the influence of dehydroemetine.

\section{REFERENCES}

Armitage, A. K. (1957). The influence of potassium concentration on the action of quinidine and of some antimalarial substances on cardiac muscle. Br.J. Pharmac. Chemother., 12, 74-78.

Bianchi, A., de Marino, V., De Vleeschhouwer, G. R. \& Marino, A. (1965). Effects of emetine on heart, coronary circulation and blood pressure (research in vitro on the guinea-pig heart and coronary flow; research in vivo on the dog heart, coronary flow and blood pressure). Arch. Int. Pharmacodyn., 156, 238-248.

Burgen, A. S. V. \& Terroux, K. G. (1953). The membrane resting and action potentials of the cat auricle. J. Physiol., Lond., 119, 139-152.

CARmeliet, E. E. (1960). The potassium chloride permeability in Purkinje fibres. In: The Specialised Tissues of the Heart, ed. Paes de Carvalho, A., DeMello, W. C. and Hoffman, B. F., pp. 108-114. New York: Elsevier.

DE Hemptinne, A. (1965). Influence of emetine on the isolated rabbit atria. Arch. Int. Pharmacodyn., 158, 239-248.

Durotoye, A. O. \& Salako, L. A. (1971). Effect of dehydroemetine on isolated preparations of rabbit and guinea-pig heart and atria. Life Sci., 10, 623-631.

Gonzalez DE Cossio, A. (1960). Electrocardiographic changes under therapy with Ro 1-9334, a synthetic racemic 2-dehydroemetine. Rev. Inst. Med. trop. Sao Paulo, 2, 313-318. 
Herrero, J., Brossi, A., Faust, M. \& Frey, J. R. (1960). Preliminary experimental and clinical results with a new synthetic emetine-like compound. Ann. Biochem. expt. Med., 20, 475-480.

Johnson, E. A. \& RoBERTSON, P. A. (1958). The stimulatory action of acetylcholine on isolated rabbit atria. Br. J. Pharmac. Chemother., 13, 304-307.

Lister, D. J. (1968). Delayed myocardial intoxication following the administration of dehydroemetine hydrochloride. J. trop. Med. Hyg., 71, 219-223.

Powell, S. J., Wilmot, A. J., MacLeod, I. N. \& ElsDon-Dew, R. (1965). A comparative trial of dehydroemetine, emetine hydrochloride and chloroquine in the treatment of amoebic liver abscess. Ann. trop. Med. Parasit., 59, 496-499.

Salako, L. A. \& Durotoye, A. O. (1971). Observations on the hypotensive response to dehydroemetine. Eur. J. Pharmac., 14, 200-203.

Sarnoff, S. J., Gilmore, J. P. \& Wallace, A. G. (1965). The influence of autonomic nerve activity on adaptive mechanisms in the heart. In: Nervous Control of the Heart, ed. Randall, W. C., pp. 54-128. Baltimore: Williams and Wilkins.

TODA, N. \& WeST, T. C. (1967). Interactions of K, Na and Vagal stimulation in the S-A node of the rabbit. Am. J. Physiol., 212, 416-423.

VAUGHAN Williams, E. M. (1958). The mode of action of quinidine on isolated rabbit atria interpreted from intracellular potential records. Br. J. Pharmac. Chemother., 13, 276-287.

(Received September 29, 1971) 